ниското заплащане, незадоволителните условия на труд и ниския социален статус на медицинските сестри, работещи в системата за първичната извьнболнична медицинска помощ, продължават да бъдат на дневен ред.

\section{Библиография}

1. Закон за съсловната организация на медицинските сестри, акушерките и асистираните медицински специалисти. Обн. ДВ/03.06.2005 г.

2. Наредба на МЗ №1/08.02.2011 г. За професионалните дейности, които медицинските сестри, акушерките, асоциираните специалисти и здрав- ните асистенти могат да извършват по назначение на лекар или самостоятелно.

3. Godinho J. Tipping the balance towards primary health care: a research project of the Commision of the European Communities // Eur. J. Public Health. 1999.

4. Marinker M. Tte End of General Practice. The 1994 Bayliss Lecture - Private Ptient Plan, 1994.

5. Mullan F. Community-oriented primary care: an agenda for the 80 's // N. Engl. J. Med.-1982.

6. The challenge for Nursing and Midwifery in the 21st. Century - the Heathrow Debate-Lond.: Department of Health, 1994.

$$
* *
$$

\title{
ПРИЛОЖИМОСТ НА СУПЕРВИЗИЯ В СЕСТРИНСТВОТО В БЫЛГАРИЯ
}

\author{
С. Тончева
}

\section{RELEVANCE OF SUPERVISION IN NURSING IN BULGARIA}

S. Toncheva

\begin{abstract}
Рез юме. В последните 15-20 години у нас бе обърнато голямо внимание на съдържателната и методичната част на академичната подготовка на медицинските сестри - да развиват знания и умения, които най-добре ще гарантират качествени грижи, съобразени със съвременните научни постижения за да отговорят на потребностите на индивида, семейството, общността. Възможностите за автономна практика на медицинските сестри насочва вниманието в световен мащаб към квалифицираните работещзи сестри, към по-нататъшното им професионално и личностно развитие, към въвличането им в дейности като супервайзори. Ние изследваме проблем, който все още търси своите практически измерения в съвременната сестринска практика и дава шанс той да бъде рано опознат, дискутиран и на първо време, може би, пилотно приложен у нас. Прилагане на супервизия в сестринството има иновативен характер, но отваря една нова врата за развитие и обогатяване на сестринската професия и нейната автономност - като размишления и като действия, приложими в България.
\end{abstract}

S $\mathbf{u} \mathbf{m} \mathbf{m}$ a ry. In the last 15-20 years, much attention has been paid to the content and methodical part of the academic training of nurses-to develop knowledge and skills, which will best ensure quality care, tailored to the contemporary scientific achievements to meet the needs of the individual, family and society. Globally, the opportunities for autonomous nursing practice focus attention to qualified, employed nurses, to their further professional and personal development and their involvement in activities as supervisors. We are exploring an issue, which is still seeking its practical dimensions in contemporary nursing practice, giving a chance to get to know and discuss it, and perhaps pilot it in our country. The implementation of supervision in nursing is innovative at its core, but opens up new horizons for the development and improvement of the nursing profession and its autonomy-as reflections and as actions that are applicable in Bulgaria.

\section{Основни нормативни документи, регламентиращи обучението и професионамната реамизация \\ на медицинската сестра у нас}

Законодателната рамка за обучението и дейността на медицинската сестра в България включва редица закони и наредби, които регламентират обучението и професионалната реализация на медицинските сестри. Без да бъдем изчерпателни в правния анализ, ще направим преглед на основните нормативни документи, които изясняват статута на професията у нас.

Съгласно чл. 8а от Наредбата за единните държавни изисквания за придобиване на висше образование по специалностите „Медицинска сестра“", „Акушерка“" и „Лекарски асистент“ [4], завършващите специалисти получават задълбочени познания по дисциплините, които са в основата на сестринските грижи, включително достатъчно високо ниво на познание за организма, психологическите функции и поведението на здравите и болните хора, както и за социалната среда на човека. Те получават познания за същността и етиката на професията и общите принципи, за- сягащи здравето и сестринските грижи, подходящ практически клиничен опит, умения за работа съвместно със здравния персонал и други медицински специалисти.

Раздел II от Наредба № 1 от 08.02.2011 г. за професионалните дейности, които медицинските сестри, акушерките, асоциираните медицински специалисти и здравните асистенти могат да извършват по назначение или самостоятелно [6] регламентира изчерпателно дейностите, които медицинската сестра може да извършва самостоятелно в областите на промоция на здравето, превенция $и$ профилактика на болестите, медицински и здравни грижи и дейности, ресоциализация, реадаптация и рехабилитация, извъриване на манипулаиии. Тези професионални дейности могат да се осъществяват от медицинската сестра както самостоятелно, така и по лекарско назначение. Наредбата регламентира и професионалните дейности, които медицинската сестра извьршва по лекарско назначение.

В чл. 81 и чл. 82 от Закона за здравето [1] са посочени основните принципи и правото на достьпна медицинска помощ за гражданите, както и обхвата на медицинските услуги, извън обхвата на задължителното здравно осигуряване. Чл. 96 от Закона за здравето дефинира палиативните медицински 
грижи: медицинско наблюдение; здравни грижи, насочени към обгрижване на пациента, премахване на болката и психоемоционалните ефекти на болестта; морална подкрепа на пациента и неговите близки. Палиативни медицински грижи се оказват от личния лекар, от лечебни заведения за извънболнична и болнична помощ и от хосписи.

Съгласно чл. 15 от Закона за лечебните заведения [2] лекарите могат да сключват договори с медицински сестри за изпълнение на медицинска дейност. А съгласно чл. 17а в медицински, медико-дентален и диагностичноконсултативен център могат да се разкриват звена, в които медицински сестри могат да оказват самостоятелно здравни грижи.

В Раздел II, чл. 6 от Наредба № 19 от 22 юли 1999 г. за водене на регистьр на лечебните заведения за извънболнична помощ и хосписите [7] е посочено, че в регистъра на лечебните заведения длъжностно лице води азбучен указател, в който се отразяват и видовете дейности, за които е регистрирано заведението.

Методично указание № 3 от 29.03.2000 г. за устройството и дейността на лечебното заведение ХОСПИС регламентира дейностите, които се осъществяват в хосписа. Дейностите в хосписа се осигуряват от лекари от лечебните заведения за първична извънболнична помощ; специалисти-консултанти при предписание от лекарите от лечебните заведения за първична извънболнична помощ; медицински сестри; социални работници, според потребностите. Координатор на грижите за всеки пациент на хосписа е медицинската сестра. Със заповед на директора (управителя) на хосписа се определят: сестра - координатор на грижите в хосписа; сестра - координатор на грижите в дома на пациента; социален работник - координатор на социалната работа; координатор на доброволците - сьтрудници на хосписа.

Съгласно чл. 80 , ал. 1 , т. 2 от Закона за лечебните заведения [2], персоналът в лечебните заведение се състои и от медицински специалисти с образователно-квалификационна степен (ОКС) ,бакалавър“" или ,магистър“ по здравни грижи.

Съгласно чл. 6 дейността на лечебните заведения и на медицинските и другите специалисти в тях, се осъществява при спазване на медицинските стандарти за качество на оказваната медицинска помощ и осигуряване защита на права̀та на пациента. Никое лечебно заведение не може да отказва медицинска помощ на лица, явили се в него в състояние, което застрашава техния живот, независимо от местоживеенето им.

Съобразно чл. 1, ал. 2 от Закона за съсловната организация на медицинските сестри, акушерките и асоциираните специалисти цел на професионалното развитие на медицинските сестри [3] е да се поддържат, повишават и разширяват теоретичните знания и практическите умения, необходими за осигуряване на качествени здравни грижи. При упражняване на професията си медицинската сестра осъществява диагностика на нуждите, промотивни, профилактични, клинични и рехабилитационни здравни грижи в съответствие с професионалните ѝ компетенции.

Българската асоциация на професионалистите по здравни грижи представлява своите членове и защитава професионалните им права̀ и интереси; създава и води национален електронен професионален регистър и регионални професионални регистри на членовете си; определя условията и реда за вписване в регистри на медицинските сестри, акушерките и асоциираните медицински специалисти и правилата за издаването на сертификат за квалификация по професията; приема Кодекс за професионална етика на медицинските сестри, акушерките и асоциираните медицински специалисти и упражнява контрол по спазването му; приема Правила за добра медицинска практика по здравни грижи, предлага ги за утвърждаване от министъра на здравеопазването и упражнява контрол по спазването им; налага санкциите, предвидени в този закон; организира, координира и регистрира продължаващото обучение на медицинските сестри, при условия и по ред, определени в договори с висшите медицински училища и с базите за следдипломно обучение; приема Квалификационна рамка за професионално развитие на медицинските сестри, състояща се от квалификационни нива̀; участва със свой представител със съвещателен глас във Висшия медицински съвет към министьра на здравеопазването; дава становища по проекти на нормативни актове в областта на здравните грижи, осъществявани от медицинските сестри; осъществява сътрудничество с други органи, организации и институции в страната и чужбина; подпомага своите членове и техните семейства в случай на нужда съгласно устава на организацията; извършва други дейности, предвидени в устава ѝ. Последните изменения в този Закон (ДВ. бр.103 от 27 Декември 2016 г.) очертават нови регламенти в практиката на медицинските сестри:

(2) (нова) Цел на професионалното развитие на медицинските сестри, акушерките и асоциираните медицински специалисти е да се поддържат, повишават и разширяват теоретичните знания и практическите умения, необходими за осигуряване на качествени здравни грижи.

4. (нова) "Квалификационни нива̀” са нива̀ на професионално развитие на медицинските сестри, акушерките и асоциираните медицински специиалисти, които отразяват придобитите знания, умения и компетентности, усвоени в рамките на продължаващзото медицинско обучение и/или специалност в системата на здравеопазването за период 5 години.

7а. (нова) приема Квалификаџионна рамка за професионално развитие на медицинските сестри, акушерките и асоциираните медицински специалисти, състояща се от квалификационни нива̀;

В Наредба № 1 от 22.01.2015 г. за следдипломно обучение в системата на здравеопазването [8] се дефинира продължителната квалификация като непрекъснато обучение след придобиването на правото за упражняване на професия под формата на курсове, индивидуално обучение, програми за професионална квалификация за придобиване на определена правоспособност, както и програми за дистанционно обучение. Обучението за придобиване на специалност и за продължителна квалификация се провежда в лечебни и здравни заведения, които са „бази за следдипломно обучение”. Специалност могат да придобиват правоспособни специалисти с висше образование по здравни грижи и завършили медицински колеж.

НАРЕДБА за единните държавни изисквания за придобиване на висше образование по специалността „Управление на здравните грижи" за образователно-квалификационните степени ,магистьр" и ,бакалавър" от професионално направление ,Обществено здраве" [5] урежда дисциплините и хорариума при провеждането на обучението.

Посочените параметри за образование, квалификации и компетентност на медицинските сестри определя тяхната решаваща роля при реализиране на здравни услуги. Към настоящия момент ролята на професионалиста по здравни грижи е различна и много динамична. Европейска практика е професионалистьт по здравни грижи да се приеме за равноправен партньор в екипа както в предоставянето на медицински и здравни грижи, така и в управлението. Но до известна степен продължаващото и професионално развитие зависят от личната мотивация и доброто желание на самите 
здравни специалисти. Добрата теоретична и практическа подготовка, както и познаването на етичните норми и добросъвестност при изпълнение на професионалните ангажименти на медицински сестри, е предпоставка за повишаване на качеството на здравните грижи. Непрекъснатото обучение на медицинските специалисти е изключително важно и необходимо в условията на лавинообразно развитие на медицинската техника и извършване на високоспециализирани грижи и манипулации. Продължаващото обучение на професионалистите по здравни грижи е важен елемент в системата на здравеопазването и гаранция за по-високо качество на здравните грижи.

Анализирайки законодателството, което урежда обучението и професионалната реализация на професионалистите по здравни грижи, в частност медицинските сестри у нас, смятаме, че за въвеждането на супервизия и утвьрждаване на наставничеството в сестринството би трябвало да се направят някои допълнения в следните закони и наредби:

- Закона за съсловната организация на медицинските сестри, акушерките и асоциираните специалисти, за да се определи: в Квалификационната рамка за професионално развитие на медицинските сестри квалификационното ниво на супервайзора и наставника;

- Наредба № 1 от 22.01.2015 г. за следдипломно обучение в системата на здравеопазването - да се добави: и специализация ,Клинична супервизия";

- Закона за лечебните заведения - сьгласно чл. 17а в медицински, медико-дентален и диагностично-консултативен центьр могат да се разкриват звена, в които медицински сестри могат да оказват самостоятелно здравни грижи - да се добави: под контрол на супервайзор;

- Закона за здравето-Чл. 96 дефинира палиативните медицински грижи: медицинско наблюдение; здравни грижи, насочени към обгрижване на пациента, премахване на болката и психоемоционалните ефекти на болестта; морална подкрепа на пациента и неговите близки. Палиативни медицински грижи се оказват от личния лекар, от лечебни заведения за извънболнична и болнична помощ и от хосписи - да се добави: и от медицински сестри под контрол на супервай3ор;

- Методично указание № 3 от 29.03.2000 г. за устройството и дейността на лечебното заведение ХОСПИС - да се добави: сестринските дейности се извършват под контрол на супервайзор. Координатор на грижите за всеки пациент на хосписа е медицинската сестра/супервайзор.

Предложението е в съответствие със стратегическите документи на правителството: Програма на правителството за стабилно развитие на Република България за периода 2014-2018 г. [11] и Концепция „Цели за здраве 2020“ [13]. В Програмата на правителството са предвидени конкретни мерки за подкрепа на системата на продължаващото обучение в системата на здравеопазването. Според Концепция „Цели за здраве 2020“ здравните професионалисти на бъдещето трябва да бъдат подкрепени от лесен достъп до възможности за учене през целия живот. Здравните професионалисти трябва да са способни да актуализират своите знания и умения и да реагират на новите здравни предизвикателства. Тази цел според Концепцията ще се постигне чрез усъвършенстване на системата за обучение и квалификация, гарантираща качеството на медицинската помощ, чрез развитие на системата за продължаващо медицинско обучение и повишаване на контрола и отговорността на съсловните организации на медицинските специалисти при организирането и провеждането на обучението. Концепцията също в раздела „Човешки ресурси“ - Основни дейности за реализация на изелите предвижда „Създаване на условия за разширяване на функциите на специалистите по здравни грижи, с което да се даде възможност за осъществяване на специфични дейности и услуги, свързани с дългосрочни грижи, палиативни грижи и др., “ което също подкрепя предложението ни за въвеждане на супервизия.

Развитието на медицинската наука и технологии поставя високи изисквания към квалификацията на медицинските специалисти, което налага непрекъснатото ѝ поддържане и повишаване. Сигурността и безопасността на пациентите е в пряка зависимост от квалификацията на всички медицински специалисти. Качеството на здравните грижи е от ключово значение за гарантиране на високо ниво на защита на здравето и безопасността на хората и за доверието в системата. Това е водещата причина за предлаганото изменение и допълнение към законодателството, което урежда обучението и професионалната реализация на медицинските сестри.

Целта е законово да се регламентира професионалното развитие на специалистите по здравни грижи. Професионалното развитие на медицинските сестри да гарантира поддържането, повишаването и разширяването на теоретичните знания и практическите умения, необходими за осигуряване на качествени здравни грижи. Професионалното развитие да се отразява в квалификационни нива̀, определени в квалификационна рамка, приета от Българската асоциация на професионалистите по здравни грижи. Квалификационните нива̀ да удостоверяват придобити знания, умения и компетентности, усвоени в рамките на продължаващото медицинско обучение или придобита специалност в системата на здравеопазването за период от пет години. Необходимо е прецизиране на понятието „добра медицинска практика“ в областта на здравните грижи, предоставяни от медицинските сестри. Въвеждането на квалификационните нива да създаде условия за реализация на целите и мерките, предвидени в Програмата на правителството за стабилно развитие на Република България за периода 2014-2018 г. и Концепция „Цели за здраве 2020“. Трябва да се отговори на високите изисквания към квалификацията на медицинските специалисти и по този начин гарантиране на сигурността и безопасността на пациентите; да се гарантира високо ниво на защита на здравето и безопасността на гражданите и доверие в системата на здравеопазването.

Към настоящия момент резултатите от продължаващото обучение обаче не са обвързани с професионалното развитие. На този етап участието в продължаващото обучение е единствено в зависимост от стремежа и желанието на професионалистите по здравни грижи за лично и професионално усъвършенстване. Здравеопазната ни система се лишава от ресурса в лицето на висококвалифицирани медицински сестри, които под контрол на супервайзор могат да осъществяват автономна дейност в интерес на здравето на пациента.

Може да обобщим, че съществуващата законодателна рамка, въпреки своята непълнота, е добра възможност за развитие на модерно сестринство в България, което включва супервизия.

\section{Модел и континиум на супервизия, приможими в Бъмгария}

Въпреки някои различия, отразяващи спецификата на всяка страна разглеждана поотделно, медицинската сестра се разглежда като централна фигура във всички модерни здравни системи. Голяма част от страните в Европа са променили своето здравно законодателство, така че по-добре да съответства на потребностите и нуждите на населението и определят сестринството като важен ресурс за всяка здравна система - дадени са възможности сестрите да управляват своите практики в рамките на придобитите компетенции и да носят отговорност за качеството на здравните грижи. Ме- 
дицинските сестри в съвременния свят споделят нова философия на грижите и ги предлагат на пациентите през различни организационни модели, стремейки се да подобрят своята ефективност, да направят цената равно достъпна. Познати са дългосрочни грижи, интегрирани социално-медицински грижи, пациент-центрирани грижи, управление на случай и др. Независимо какъв модел на оказване на грижи прилагат сестрите в различните страни, общ е стремежът да се търсят пътища грижите да имат гарантирано качество и непрекъснат характер.

В България медицинските сестри имат различно ниво на компетентност:

различни образователни степени;

различен стаж в професията (опит);

- различно следдипломно обучение (краткосрочно, специализации, придобити бакалавърски и магистърски степени по Управление на здравните грижи и др.);

- придобит първи или втори Сертификат, както и такива, които не са сертифицирани (професионална карта).

Следователно е необходим професионален „поглед отгоре“, който може да бъде възложен на подготвената, специално обучена за това медицинска сестра.

Грижите, независимо дали се предоставят в общността или в институционална среда, са процес, изискващ интензивното участие на трудовия фактор - лекари, медицински сестри, акушерки, психолози, педагози, социални работници и др., като непрекъснатото обучение е предпоставка за поддържане на високо качество на предлаганите здравни грижи.

Общата тенденция е деинституционализиране на грижите - с изключение на хората с тежки увреждания, и предлагане на съобразени с индивидуалните потребности грижи в домашни условия и грижи в общността, както и внедряване на съвременните технологии - електронно здравеопазване, теленаблюдение, телемедицина и др., които ще улеснят грижите. Всичко това налага осигуряване на подготвени здравни професионалисти.

Участието на медицинските сестри в осъществяване на политики за превенция и рехабилитация, насочени към насърчаване воденето на активен и здравословен начин на живот изисква наличието на добре обучен и квалифициран персонал и ефикасно използване на информационните и комуникационни технологии, прилагане на иновотивни подходи и неизбежно въвеждане на супервизия.

\section{Модел на супервизия в България}

1. Организационно-технологичната рамка на супервизията в институционален контекст

- конструктивна и редовна обратна връзка със супервизираните медицински сестри и здравната структура (болница, отделение, клиника и др. или здравна грижа); месечно);

- периодично провеждане на супервизия (поне 1 път

- познаване на трудностите и проблемите на персонала и използване на възможностите на индивидуалната и груповата супервизия за преодоляването им;

- познаване на потребностите на персонала и перспективите за неговото развитие;

- преодоляване на недоверие и негативизъм към възможностите на супервизията;

- приемственост в дейността на супервизорите.

2. Използване на различни видове и форми на супервизия (оптимално съчетаване на различните видове и форми, като се дава приоритет на индивидуалната супервизия)

Видове супервизия

- Индивидуална супервизия

- Групова супервизия
Форми

• използване на дистанционната форма на супервизия (онлайн супервизия) в съответствие с нейните възможности;

• редовно използване на административна, образователна и подкрепяща супервизия;

- доминиране на супервизията между колеги.

3. Основни цели на супервизията в сестринството Да се подобри качеството на работата:

- да се подкрепи и насърчи медицинската сестра и да ѝ се вдъхне увереност в работата;

- да се наблюдава и да се практикува - да се дадат на медицинската сестра знания и умения, които да ѝ позволяват да върши по-добре работата си;

- да се проследява качеството - да се приложат механизми за контрол на качеството и насърчаване на медицинските сестри да прилагат стандарти и правила за „добра здравна грижа“.

Осигуряване на най-добрата защчта за паџуиетите при сложни клинични ситуациии:

- прилагане на индивидуален подход;

- анализ на състоянието и оценка на потребностите на пациента;

- планиране на грижите в съответствие с целите, които си поставя медицинската сестра;

- сестрински интервенции, съответстващи на законово регламентирани професионални компетенциите (изключване на риск за пациента).

Предпазване на медииинската сестра от ,, бърнаут “:

- дейности на институцията за намаляване на стреса (анти-стрес програми);

- обратна връзка със супервайзора;

- самооценка за извършени дейности от медицинската сестра (рефлекс над сестринската практика).

Предлагаме Модел на супервизия, който може да бъде приложен в България (Фигура 1).

Фигура 1. Модел на супервизия, приложим в България

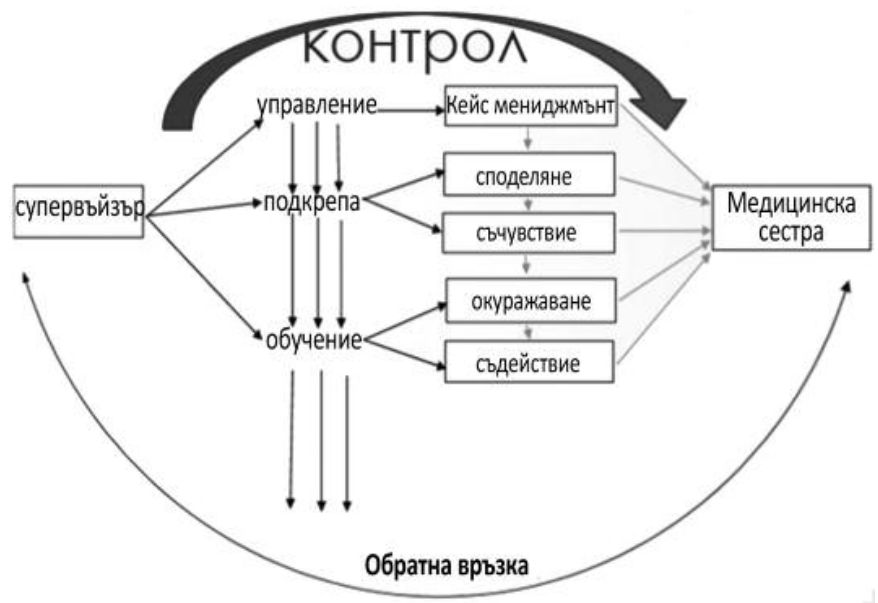

4. Очакваните ефекти от прилагане на супервизията биха могли да се изразят в следното (Фигура 2): сестра

- подкрепа на кариерно развитие на медицинската

- разширяване на знанията;

- подпомагане на клиничните умения;

- намаляване на стреса;

- намаляване на риска за пациента;

- издигане на имиджа на професията;

- принос за признаване на автономия в рамките на професионалните компетенции на медицинската сестра. 
Фигура 2. Ефекти от въвеждане на клинична супервизия в сестринството

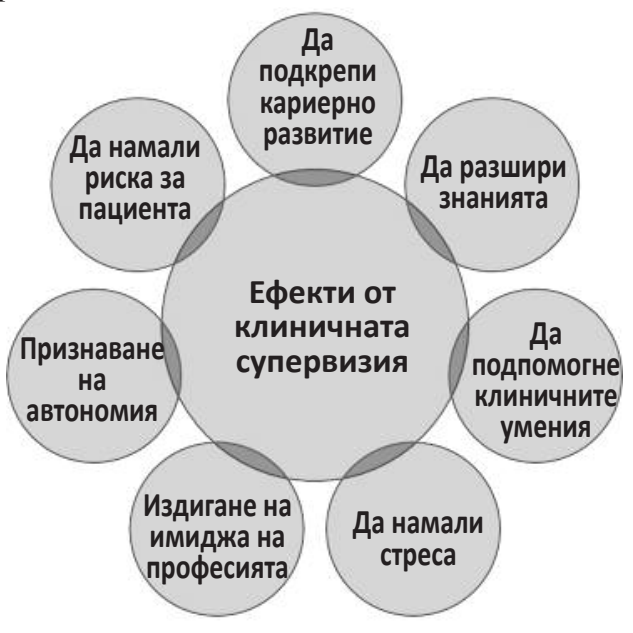

Модел на супервайзор професионални компетенции

и подкрепа;

-установяване на атмосфера на доверие, сигурност

- спазване на приети отговорности;

- сътрудничество и обмен на идеи и решения;

- обсъждане на очаквани трудности и проблеми в съвместната дейност;

- разясняване на значението на супервизията като важен елемент на сестринската работа;

- отговорност и инициативност - провеждане на редовни работни срещи,

-осъществяване на посредничество между ръководител на социалната служба или услуга и персонал при трудности във взаимодействието;

- анализиране на проблеми и ситуации на затруднение; первизирания;

- поддържане на действена обратна връзка със су-

- балансирано упражняване на власт;

-съобразен с културната принадлежност и недискриминиращ стил на комуникиране и поведение; работа.

- съобразяване с етичните принципи на сестринската

Смятаме, че за България има възможност да се предложи Континиум на супервизията в сестринството (Фигура 3). Фигура 3. Континиум на супервизията в сестринството в България
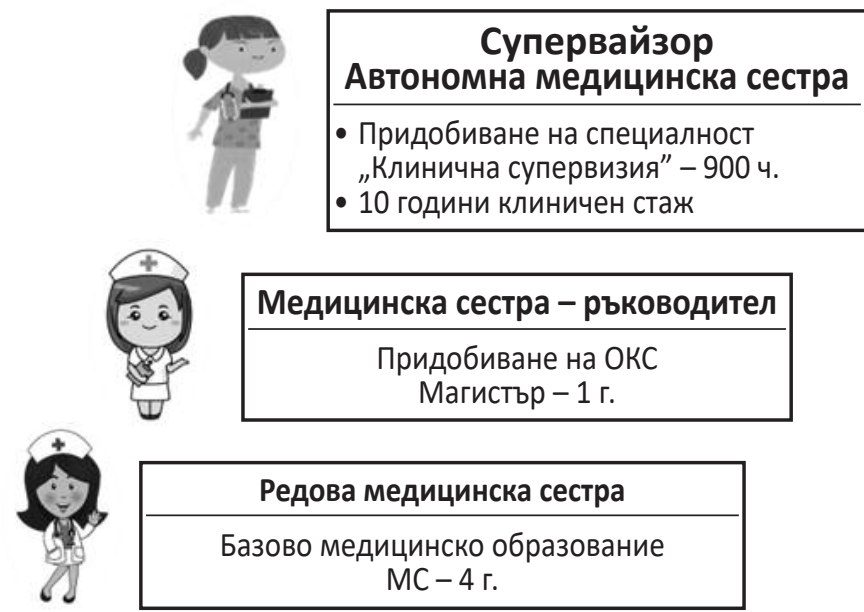

\begin{tabular}{|c|}
\hline Редова медицинска сестра \\
\hline Базово медицинско образование \\
MC - 4 г. \\
\hline
\end{tabular}

Сыщността на Континиума може да се изясни в три стъпки, от които двете са законодателно уредени в България:

1. Базово образование за придобиване на специалност „Медицинска сестра“ с ОКС „Бакалавър“- срок на обучение 4 години в Университет, достатъчно условие за практикуване на професията като редова медицинска сестра;

2. Придобиване на ОКС „Магистьр“- срок на обучение 1 г. в университет, достатъчно условие за заемане на ръководни дльжности, и в т.ч. и шеф екип в клинични звена, ако магистърската програма е с клинична насоченост;

3. Необходимо условие - 10 години клиничен стаж, придобиване на специалност „Клинична супервизия“ и право на автономна сестринска практика като супервайзор.

За третата стьпка е необходимо допълване на законовата рамка, включване на специалност „Клинична супервизия“ и право на автономна практика на медицинската сестра.

По този начин супервайзорьт ще има ,Поглед отгоре“. Фигура 4. Супервизия в сестринството - „поглед отгоре“

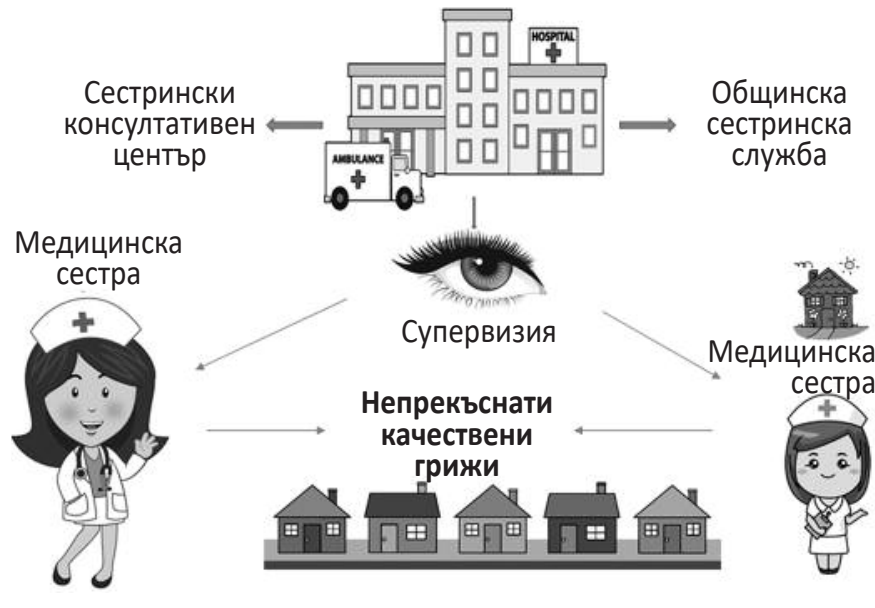

\section{Закиючение и изводи}

- Анализът на законовата рамка, засягащ обучението и практиката на медицинската сестра в България създава възможност за конкретизиране на дейността на супервайзора, позиция, която могат да заемат медицински сестри с потенциал за развитие.

- Все още не е ясно дали сестринската професия може да се справи с последиците от самостоятелността и отговорностите. Необходим е супервайзор - подготвена медицинска сестра, която да има „поглед отгоре“ и ограничава допускането на грешки във вреда на пациента.

- За прилагане на клинична супервизия в сестринската практика у нас е необходимо допълнително обучение на утвърдени в практиката медицински сестри с достатъчно опит (10 години), комуникативни умения и желание за развитие като супервайзор, в унисон с традициите в сестринството и националния контекст.

- Подкрепящата професионална роля на клиничен супервайзор може да допринесе за по - висока мотивация на сестрите, предпазване от „прегряване“ и поддържане на високо качество на здравните грижи.

- Предложените Модел на супервизия и Континуум на супервизията в сестринството, на базата на проучената литература могат да бъдат добра основа за прилагане на научен подход и създаване на възможност медицинските сестри да обсъждат въвеждане на супервизия в България.

- Въвеждане на Супервизия в сестринството у нас може да допринесе за промяна в качеството на здравните грижи, автономна дейност на медицинската сестра и издигане имиджа на професията. 


\section{Библиография}

1. Закон за здравето, ДВ. бр.70 от 10.08.2004 г., последно изм. и доп 2018 г.

2. Закон за лечебните заведения, ДВ. бр.62 от 9.07.1999 г., последно изм. и доп. 2018 г.

3. Закон за съсловната организация на медицинските сестри, акушерките и асоциираните специалисти цел на професионалното развитие на медицинските сестри, ДВ. бр.46 от 3.06.2005 г., последно изм. и доп. 2016 г.

4. Наредба за ЕДИ за придобиване на висше образование за специалностите „Медицинска сестра” и „Акушерка” за ОКС „бакалавър”, изм. ДВ. Бр.88 от 9.11.2010.

5. Наредба за ЕДИ за придобиване на висше образование по специалността "Управление на здравните грижи" за образователно-квалификационните степени “магистър” и “бакалавър" от професионално направление "Обществено здраве” ДВ. бр.95 от 29.11.2005 г., последно изм. и доп. 2016

6. Наредба № 1 от 08.02.2011 г. за професионалните дейности, които медицинските сестри, акушерките, асоциираните медицински специалисти и здравните асистенти могат да извършват по назначение или самостоятелно ДВ. бр. 15 от 18.02.2011 г.
7. Наредба № 19 от 22 юли 1999 г. за водене на регистьр на лечебните заведения за извънболнична помощ и хосписите ДВ. бр.68 от 30.07.1999 г., последно изм. 2009 г.

8. Наредба № 1 от 22.01.2015 г. за следдипломно обучение в системата на здравеопазването, ДВ, бр. 7 от 27.01.2015 г.,

9. Национална здравна стратегия (2014-2020) (НЗС), приета с Решение на Народното събрание от 17.12.2015 г

10. Национална програма за развитие на България 2020, приета с Решение № 1057 на Министерския съвет от 20.12.2012 г.

11. Програма на правителството за стабилно развитие на Република България за периода 2014-2018 г., приета с Решение № 42 на Министерския съвет от 26.01.2015 г.

12. Национална стратегия за дългосрочна грижа, приета с Решение № 2 на Министерския съвет от 07.01.2014 г.

13. “Цели за здраве 2020“ - Концепция http://www.mh.government.bg/media/filer_public/2015/04/08/kontseptsiya-tseli-za-zdrave-2020.pdf

\section{Автор}

Профр. д-р Соня Тончева, Медицински университет - Варна

\title{
ПРОБЛЕМИ НА БЪЛГАРСКАТА ЗДРАВНА СИСТЕМА СПОРЕД ЖАЛБИТЕ И СИГНАЛИТЕ НА ПАЦИЕНТИТЕ КЪМ КЗД, ИАМО И СЪДА
}

\author{
Н. Джафер
}

\author{
PROBLEMS OF THE BULGARIAN HEALTH SYSTEM ACCORDING \\ TO COMPLAINTS AND SIGNALS OF THE PATIENTS TO CPD, EAMO \\ AND THE COURT \\ N. Dzhafer
}

Рез юме. Всяка здравна система има една основна задача - да решава здравните проблеми на хората. Потребителите на здравни грижи могат да изпратят своите жалби и сигнали за нередности към различни органи и институции. Работата включва преглед на подадените жалби и сигнали, свързани със здравеопазването към Комисията за защита от дискриминация (КЗД) (380 броя), Изпълнителната агенция „Медицински одит” (ИАМО) (3472 броя) и съдебната система (238 дела). Разгледани са периодите на съществуване на КЗД И ИАМО и десетгодишен период при съдилищата. Използвана е достьпната информация за дейността на тези институции, както и поискана специална за целта на тази публикация информация. Броят на жалбите, отправяни към дадена институциия най-вероятно се влияе от доверието към нея, начина на подаване и проиедурата по сезиране, уведомяването за проверката и резултата от нея.

S u m m a ry. Each healthcare system has one main task - to solve the health problems of people. Healthcare users can send their complaints and signals of irregularities to different bodies and institutions. The work includes a review of healthcare complaints and alerts submitted to the Commission for Protection from Discrimination (380), the Executive Agency,,Medical Audit" (3472) and the Judiciary (238 cases), examining the periods of existence of CPD and EAMO and a ten-year period in the courts. Useful information on the activities of these institutions, as well as information specifically requested for this publication, has been used. The number of complaints addressed to an institution is most likely influenced by its credibility, the way of filing and the referral, the notification of the investigation and its outcome.

Key words: Patient Complaints, Commission for Protection against Discrimination (CPD), Medical Audit Executive Agency (EAMO), Court

\section{Въведение}

Основно право на пациента според Хартата за права̀та на пациентите е правото му на подаване на жалби, ако не са спазени права̀та му като такъв. Класическата деонтология е в основата на медицинското право, което по презумпция трябва да се базира на стандартизиране, правила, алгоритми, които могат да се обективизират и оценят. От тук произтича важността на т. нар. правила за добра медицинска практика, медицински стандарти, клинични пътеки като метод за поведение и разплащане и най-вече като начини за стандартизация и оценка за спазване. Отговорността в здравеопазването е административноправна и наказателноправна. Тя може да е гражданска или съсловна, както и морално-етична $[5,7,8]$. Освен към институции със специално вменени за- дължения и създадените специфични за целта структури за контрол и надзор в здравеопазването (ИАМО) [3], граждани и организации могат да сигнализират други органи за проблеми в здравната система. Омбудсманът на Р. България [2] и Комисията за защита от дискриминация (КЗД) $[1,4]$ ако бъдат сезирани или се самосезират, са институции и органи с по-широки правомощия, които включват и правомощия, и ангажименти, свързани със здравеопазването.

\section{Цем и заАачи}

Целта и свързаните с нея задачи са да се анализират броят на подадените жалби, тенденцията за промяна в броя им, видовете проблеми, които засягат. Необходимо е да се направи следното уточнение: Освен, че са регламентирани 